\title{
Identification of the Influence of Concrete Cover Thickness and $\emptyset / \rho$ Parameter on Crack Spacing.
}

\author{
Chavin N. Naotunna, S.M Samindi M.K Samarakoon and Kjell T. Fosså
}

\author{
Department of Mechanical and Structural Engineering and Material science, Faculty of \\ Science and Technology, University of Stavanger, Stavanger, Norway, chavin.guruge@uis.no
}

\begin{abstract}
Cracks due to the service load in the reinforced concrete structures are controlled at the design stage, by limiting the calculated crack width. Widely used crack width calculation models (Eurocode 2 and Model code 2010), estimates the crack width by multiplying the crack spacing with the mean strain difference of concrete and reinforcement. Concrete cover thickness and the ratio of diameter to reinforcement area to effective tensile area of concrete $\left(\varnothing / \rho_{p, e f}\right)$ are the two main crack spacing governing parameters in the aforementioned models. The existing models are mostly applicable when concrete cover thickness is within the specified limit. For example, Model Code 2010 model limits the concrete cover thickness to $75 \mathrm{~mm}$. In order to identify the influence of aforementioned two governing parameters on crack spacing, the results of recent experiments have been considered. According to some recent studies, it is found that the concrete cover thickness has a significant influence and the $\emptyset / \rho_{p, e f}$ parameter has a negligible effect on crack spacing. To investigate the reasons why the $\emptyset / \rho_{p, e f}$ parameter has a negligible effect on crack spacing, the involvement of bond properties is needed to study. Some authors have specified that the large diameter bars consist of higher bond force per unit surface area than the small diameter bars, due to the high rib area. Due to this reason, the similar bond behavior could be identified, from low number of large bar diameters and high number of small diameter bars. A literature review has been carried out to study the bond behavior on specimens subjected to pure tension. With the facts and available data, it is further verified that the $\emptyset / \rho_{p, e f}$ parameter has a negligible influence and concrete cover thickness has a significant effect on crack spacing.
\end{abstract}

Keywords: Crack Spacing, Concrete Cover, Bond Stress-Slip, Axial Tension.

\section{Introduction}

Cracks in the reinforced concrete (RC) structures create issues to the durability, aesthetic appearance and the liquid or gas tightness of the structure. Among the various types of cracks that can generate in a structure, the cracks due to service load is controlled at the design stage by limiting the calculated crack width. In the most widely used codes of practices (Ex. Eurocode 2, 2004; Model code 2010, 2013; etc.), the calculated crack width is governed by multiplying the crack spacing with the mean strain difference between reinforcement and concrete. Therefore, the crack spacing parameter can be identified as an important factor in crack controlling criteria. However, it has identified many limitations in the above-mentioned available crack controlling methods (Ex. limitation for the maximum value of concrete cover thickness). Further, there are many experimental evidences from previous literatures, that the experimental predictions do not match with the code prediction values.

In the aforementioned codes, the concrete cover thickness and $\varnothing / \rho_{\mathrm{p} \text {,ef }}$ parameter (ratio of diameter to reinforcement area to effective tensile area of concrete) have identified as the two most governing factors of the crack spacing model. In order to improve the existing models, the authors have studied the behavior of aforementioned parameters with the help of available literatures. The crack width or crack spacing models developed in the mentioned codes are based on the axial tension experiments of an RC tie subjected to pure tension. Because a RC tie in pure tension can be represented the tensile region of a bending member with or without axial tension (Debernardi et al., 2013). There are many previous experiments reported, which have 
studied about the cracking behavior of RC members. Among them, it can be found various types of data to identify the crack width governing parameters. However, with the advancement of material and geometrical properties of concrete and reinforcement, the authors have selected two recent axial tensile experiments mentioned in (Tan et al., 2018; Tan et al.,2019) and (Rimkus and Gribniak, 2017), to identify the crack spacing governing parameters. The selected experiments consist of the RC ties with multiple reinforcement bars, which are more similar to the RC members in practice.

The concrete cover parameter and $\emptyset / \rho_{\mathrm{p}, \mathrm{ef}}$ parameter is available in the existing crack governing models are due to the 'no-slip theory' and 'bond-slip theory' respectively (Saliger,1936; Broms, 1965). The 'no-slip theory' assumes a perfect bond between reinforcement and surrounding concrete. The 'bond-slip theory' considers that a slip occurs between the reinforcement-concrete interface. From the selected experimental data, it could identify that concrete cover thickness has a significant impact on crack spacing, and therefore to the crack width. When considering the effect of $\emptyset / \rho_{\text {p ef }}$ parameter, it could identify that the parameter has a negligible effect on the crack spacing (Beeby, 2004; Rimkus and Gribniak, 2017). When trying to identify the reasons for this controversial conclusion, Alander in (Beeby et al., 2005) makes a statement, that when the bar diameter increases, the rib area also increases (even with similar rib pattern). This increased rib area in larger bar diameters cause to have a higher bond force per surface unit area, than the smaller bar diameters (Noghabai, 1995). This effect is not considered in the existing EC2 or MC 2010 models. The mentioned models assume the bond-stress is only that the mean bond stres tensile strength of conc

Balaz (1993), introd known Ciampi-Eligehausen (Cia Ciampi-Eligehausen, bond-slip model is based on Rilem-type pull-out test (RILEM, 1994)

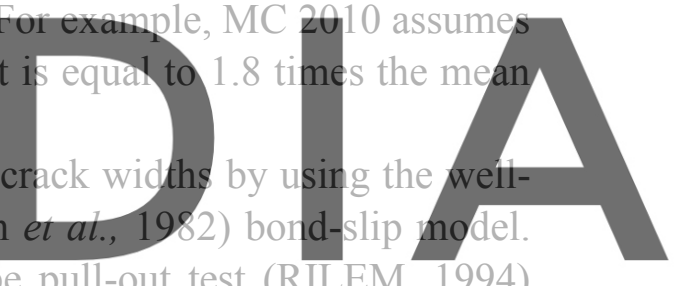

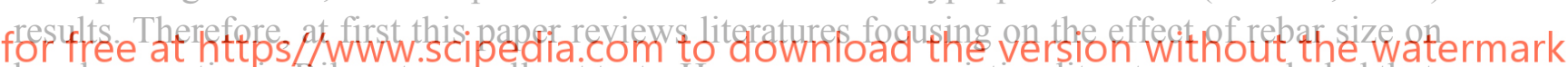
bond properties in Rilem-type pull out tests. However, many existing literatures concluded that, bond strength and stiffness decrease with the increase of bar diameter (which is opposite to the expected results). Therefore, this paper investigates the actual bond-slip behavior of specimens subjected to 'axial tension'.

\section{The Behavior of Concrete Cover and $\emptyset / \rho_{\mathrm{p}, \text { ef }}$ Parameter on Crack Spacing from the Recent Experiments}

Table 1 shows the test results of axial tensile experiments of RC ties mentioned in Tan et al.,(2018) and Tan et al., (2019). Table 1 confirms that the increase of concrete cover, cause to increase crack spacing. When comparing the specimen 1 and 3, with the increase of concrete cover, the maximum crack spacing (Table 1) increases. Likewise, the crack spacing values and specimen 2 and 4 behaves similarly.

Table 1. Crack spacing values measured in stabilized cracking stage (Tan et al., 2019).

\begin{tabular}{|c|c|c|c|c|c|c|c|}
\hline $\begin{array}{c}\text { Specimen } \\
\text { No. }\end{array}$ & $\begin{array}{c}\text { Width } \times \text { height } \times \\
\text { length }(\mathrm{m} \times \mathrm{m} \times \mathrm{m})\end{array}$ & $\begin{array}{c}\text { No. of } \\
\text { bars }\end{array}$ & $\begin{array}{c}\text { Diameter } \\
(\mathrm{mm})\end{array}$ & $\begin{array}{c}\text { Cover } \\
(\mathrm{mm})\end{array}$ & $\emptyset / \rho_{\mathrm{p}, \mathrm{ef}}$ & $\begin{array}{c}\mathrm{S}_{\mathrm{r}, \operatorname{mean}} \\
(\mathrm{mm})\end{array}$ & $\begin{array}{c}\mathrm{S}_{\mathrm{r}, \max } \\
(\mathrm{mm})\end{array}$ \\
\hline 1 & $0.4 \times 0.4 \times 3$ & 8 & 32 & 40 & 796 & 178 & 240 \\
\hline 2 & $0.4 \times 0.4 \times 3$ & 8 & 20 & 40 & 1274 & 163 & 250 \\
\hline 3 & $0.4 \times 0.4 \times 3$ & 8 & 32 & 90 & 796 & 266 & 320 \\
\hline 4 & $0.4 \times 0.4 \times 3$ & 8 & 20 & 90 & 1274 & 217 & 290 \\
\hline
\end{tabular}


Considering specimen 1 and 2 (likewise, 3 and 4) with the same concrete cover thickness, specimen size and material properties, the effect of $\varnothing / \rho_{\mathrm{p}, \text { ef }}$ parameter on crack spacing cannot be compared, due to difference in steel areas (Specimen 1 and 2 have $8 \times \pi \times 16^{2} \mathrm{~mm}^{2}$ and $8 \times \pi \times 10^{2} \mathrm{~mm}^{2}$ steel areas respectively). The same steel area can be represented with different sizes of reinforcement. If small diameter bars are used, the circumference area of the rebar are higher than when the same steel area is replaced by large diameter bars. For example, if one 16 $\mathrm{mm}$ bar is replaced with four $8 \mathrm{~mm}$ bars (similar steel area), the circumference area is doubled $[(4 \times \pi \times 8) /(1 \times \pi \times 16)=2]$. Therefore, the higher number of smaller diameter bars consist of higher concrete-reinforcement interface area than the few number of large diameter bars arrangement. When bond area becomes large, transfer length will be low. In theory, the RC specimens with similar cross-sectional area and similar steel area, the larger bar diameter has the higher $\emptyset / \rho_{\mathrm{p}, \text { ef }}$ value. According to the EC2 and MC 2010 crack spacing models, this cause to predict larger crack spacing values than the specimens with smaller bar diameter.

Rimkus and Gribniak (2017) have studied the effect of $\emptyset / \rho_{\text {p. ef }}$ on crack snacing, by keening the steel area and other previously mentioned crack spacing governing parameters constant. In the study, the different values for $\emptyset / \rho_{\mathrm{p} \text {,ef }}$ has been obtained by changing the rebar diameters. This experiment had tested 21 number of specimens with $150 \mathrm{~mm}$ x $150 \mathrm{~mm}$ (Height x width) cross section size and $30 \mathrm{~mm}$ concrete cover thickness. The study have tested three different steel areas of $315 \mathrm{~mm}^{2}, 450 \mathrm{~mm}^{2}$ and $607.5 \mathrm{~mm}^{2}$ (Steel ratio ( $\rho_{\mathrm{p}, \mathrm{ef}}$ ) of $1.4 \%, 2.0 \%$ and $2.7 \%$ respectively) and used different deformed bar sizes of $5 \mathrm{~mm}, 6 \mathrm{~mm}, 8 \mathrm{~mm}, 10 \mathrm{~mm}, 12 \mathrm{~mm}$ and $14 \mathrm{~mm}$ diameters to change the $\phi / p_{\text {p.er }}$ ratio. However, the final conchusion of the experiment is that, the crack spacing has a negligible influence from the $\varnothing$

The conclusions of the aforementioned resu agreement with the statement of Beeby (2004). experiment results of ( Farra and

Jaccoud,
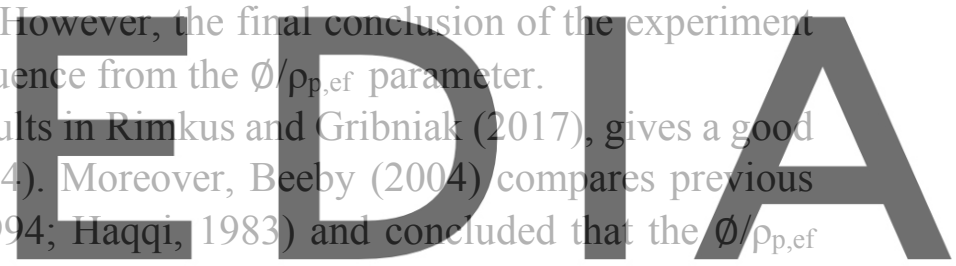

parameter does not influence on crack width or crack spacing. However, when the experiments

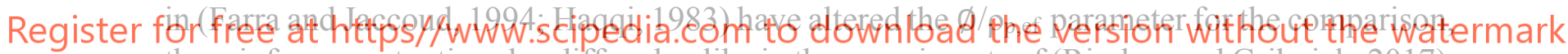
the reinforcement ratios also differed unlike in the experiments of (Rimkus and Gribniak, 2017). Therefore, the statement of Beeby (2004) is further confirmed from the experimental results of (Rimkus and Gribniak, 2017).

\section{The Involvement of The Bond-Properties to the Crack Spacing Models.}

It is vital to investigate reasons why the previous experimental findings shows that $\varnothing / \rho_{\mathrm{p}, \mathrm{ef}}$ parameter, (which appears from the 'bond-slip approach') does not influence on crack spacing. Alander, who had studied the reinforcement rib geometry on crack widths in Alander (2002), have made a good explanation for this reason in the discussion paper Beeby et al. (2005). According to their findings, the bond per surface area of every reinforcement is not similar, due to the different rib geometry. Moreover, when the diameter of a bar increases, the bond strength increases, due to the increase in rib area and height relative to the smaller bar diameters (nominal bar diameter to rib height is generally used as 22). Therefore, the assumption made on developing the existing crack spacing models that the bond stress is similar among every bar diameter have to be reconsidered.

The rib pattern or height are considered as the governing factors of the bond-strength and bond-stiffness of a reinforcement. The ratio of the nominal bar diameter to rib height is generally used as 22 in reinforcement (Metelli and Plizzari, 2014). Bond-index parameter quantitatively represent the effect of rib-pattern and rib-height of a specific reinforcement. The 
bond-index is identified as the most governing rib parameter that influences bond-strength and bond-stiffness and EC2 specifies to have a minimum bond index of 0.056 for a bar exceeding the diameter of $12 \mathrm{~mm}$. To investigate the statement made by Alander in Beeby et al. (2005) discussion paper, a literature review has been studied on the size effect of the bars on the bond between concrete and reinforcement. The details and the conclusions of some existing literatures are listed in the Table 2 .

Table 2. Summary of the previous studies on the bond behavior for size effect.

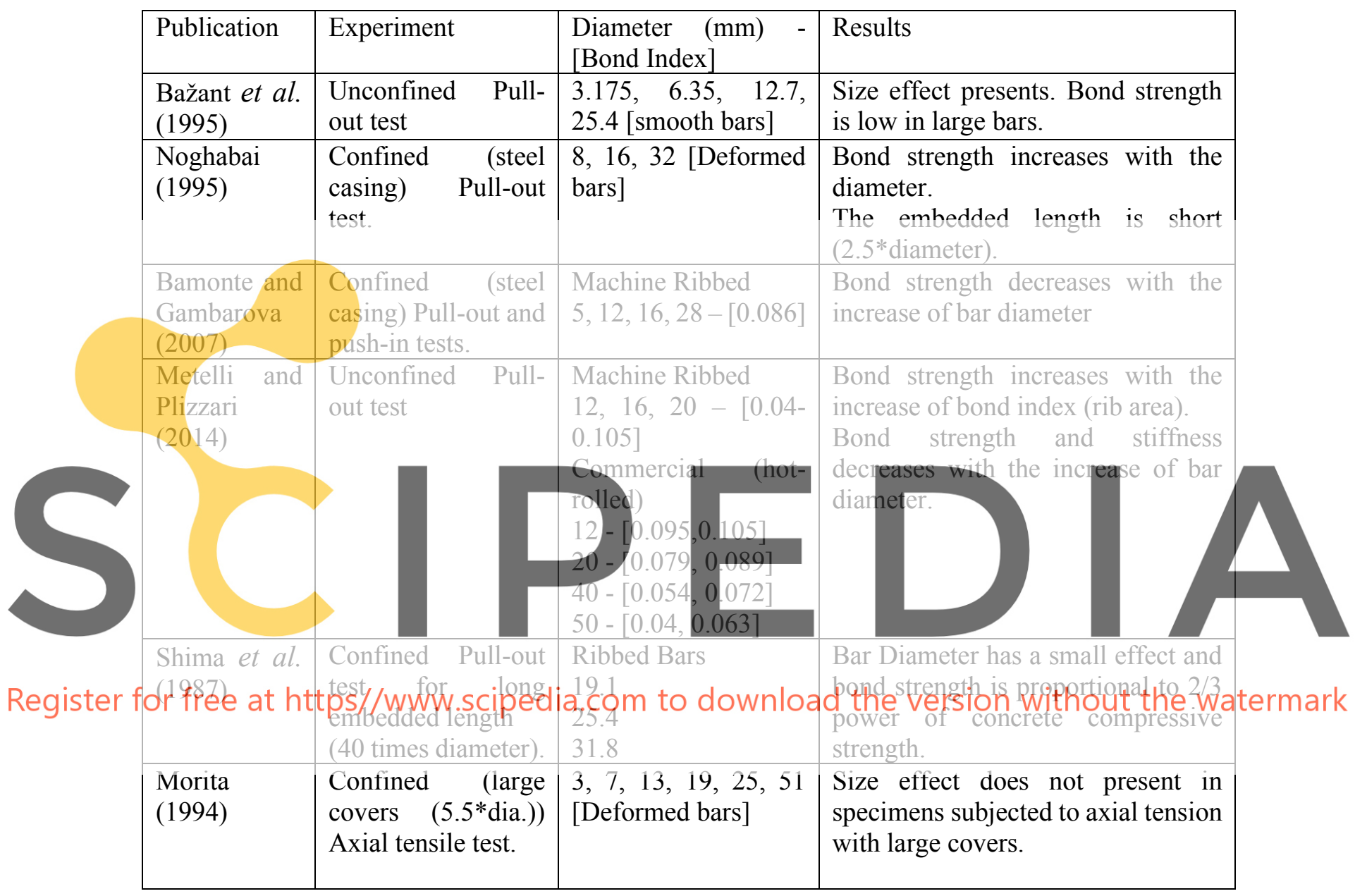

According to the Table 2, except in Noghabai (1995), other experiments have concluded that the bond strength decreases with the increase of bar diameter. These results does not agree with the previously mentioned statement by Alander in Beeby et al. (2005) discussion paper. This can lead to another direction, whether the pull-out or push-in tests represents the bond-behavior of an RC tie subjected to axial tension or flexure. The authors in (Alander, 2002; Beconcini et al., 2008; Mazzarolo et al., 2012) explains that the traditional Rilem-type tests (RILEM, 1994) does not represent the bond condition of a member subjected to bending or axial tension. The main reasons for the discrepancy are identified as the short anchorage length (embedded length is five times the bar diameter), one-way loading method (the concrete parallel to the reinforcement is in compression), failure mode (splitting failure that occurs in unconfined tests) in the standard pull-out tests. The short embedded length is decided in the Rilem-type test is to ensure the uniform distribution of the bond stress along the bar (Mazzarolo et al., 2012) and to reach the bond-failure before rebar yields (Bamonte and Gambarova, 2007; Mazzarolo et al., 
2012). In order to make the experimental conditions closer to the practical situation, Shima et al., (1987) have used longer embedded lengths (40 times diameter) and studied the size effect on bond stress (Table 2).

It has observed that the reinforcement-concrete interface in axial tensile members does not subject to the range of slip value as observed in the Rilem-type tests. The experimental investigation of the crack widths at the level of reinforcement in (Borosnyói and Snóbli, 2010; Husain and Ferguson, 1968; Tammo and Thelandersson, 2009) have proved that the slip is in the range of hundredth of a millimeter (ex. $0.01 \mathrm{~mm}$ to $0.06 \mathrm{~mm}$ ). These studies have observed the crack width propagation along the concrete cover thickness by sealing the crack, with a hardened epoxy and examining by cutting the specimen. (Borosnyói and Snóbli, 2010; Caldentey et al., 2013) have explained the reason for the relatively small crack widths at the reinforcement face. They have considered that it is due to the accumulation of strains in secondary cracks, which are identified as Goto cracks in Goto (1971). These secondary cracks are developed around the primary cracks (Debernardi et al., 2013; Debernardi and Taliano, 2016) and therefore the 'slip' is considered as spread at the vicinity of primary crack. However, Yannopoulos (1989) has conducted experiments to study the variation of crack widths along the concrete cover thickness. During, the experiment, the increase length of specimens was measured using gauges that were fixed at the both end-faces perpendicular to the reinforcement of the axial tensile tie. One measurement was obtained $2.2 \mathrm{~mm}$ away from the reinforcement and the other measurement was obtained at the edge (i.e. at a distance of concrete cover) of the

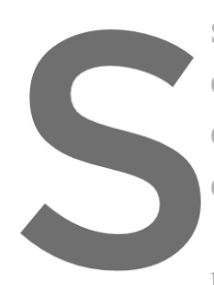
specimen. The obtaince average change in length were $0.06 \mathrm{mn}$
conclusion is that, even the internal cracks do exist, their accuin
crack widths at the concrete surface. Therefore, the internal
cracks) cannot be considered as a contributor to the slip.
The experiment mentioned in Beeby (2004), contributes to

between reinforcement and concrete interface in axial tensile members. A layer of grout is

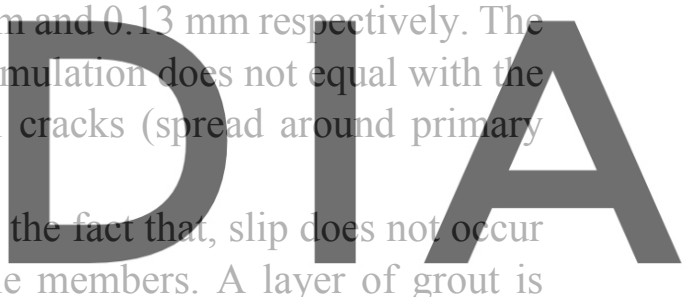

Register fopplied at the end fages of RC tie (faces perpendicular tp reinforcement) and observed po cracks in the reinforcement-concrete interface after the tensile load is applied. Due to these facts, the slip between reinforcement and concrete can be expressed as negligible and the cracking is according to the 'no-slip theory'. However, to ensure this fact, the authors have studied through the aforementioned bond-slip experiments conducted for axial tensile experiments. The method of slip and bond-stress measurements in conducted axial tensile experiments are listed in Table 3. Except for the experiment mentioned in Doerr (1978), other listed experiments have not measured the concrete strain separately to obtain the slip. Either the researcher has neglected the concrete strain or calculated it from the force equilibrium using only the reinforcement strain. There is a possibility that these calculated concrete strain can be due to 'no-slip' conditions. The experiment mentioned in Doerr (1978), which had separately measured the 'concrete strain' with strain gauges, $16 \mathrm{~mm}$ away (one diameter length) from the reinforcement face. This measurement does not represent the slip at the reinforcement - concrete interface. Based on above reasons it is not clear whether the experiments given in Table 3 have measured the actual value of slip. 
Table 3. Details of the axial tensile experiments focused on bond-slip.

\begin{tabular}{|c|c|c|c|}
\hline Experiment & Details & Bond stress & Slip \\
\hline $\begin{array}{l}\text { Doerr }(1978) \\
\text { Cylindrical specimen dia. }= \\
150 \mathrm{~mm} . \\
\text { Length }=600 \mathrm{~mm} . \\
\text { Bar dia. }=16 \mathrm{~mm} \\
\text { Strain gauge on rebar and } \\
\text { concrete. } \\
\text { Spacing }=28 \mathrm{~mm}\end{array}$ & $\begin{array}{l}\text { Concrete strain gauges } \\
\text { were placed } 16 \mathrm{~mm} \text { away } \\
\text { from concrete, while } \\
\text { casting. } \\
\text { Electrical resistance wire } \\
\text { strains were used. } \\
\text { Specimen were sectioned } \\
\text { to } 28 \mathrm{~mm} \text { size parts along } \\
\text { the length. }\end{array}$ & $\begin{array}{l}\text { Bond stress }\left(\tau_{(\mathrm{x})}\right) \\
\text { along the bar } \\
\tau(\mathrm{x}) \\
=-\frac{1}{\pi \varphi} \cdot \frac{\mathrm{dP}(\mathrm{x})}{\mathrm{dx}} \\
\mathrm{P}_{(\mathrm{x})^{-}} \text {Force in } \\
\text { reinforcement. } \\
\text { Where } \mathrm{P}(\mathrm{x}) \text { can } \\
\text { be identified by } \\
\text { interpolating the } \\
\text { steel strain at } \\
\text { each segment. }\end{array}$ & $\begin{array}{l}\begin{array}{l}\text { Slip of the } \\
\text { element } \\
\left(\mathrm{s}_{(\mathrm{a}+1)}(\mathrm{x})\right),\end{array} \\
\mathrm{s}_{(\mathrm{a}+1)}(\mathrm{x})=\varepsilon_{\mathrm{s}, \mathrm{a}} \cdot \mathrm{dx}- \\
\varepsilon_{\mathrm{c}, \mathrm{a}} \mathrm{dx} \\
\varepsilon_{\mathrm{s}, \mathrm{a}}-\text { Strain in } \\
\text { 6einforcement } \\
\varepsilon_{\mathrm{c}, \mathrm{a}}-\text { Strain in } \\
\text { concrete } \\
\text { dx - spacing of } \\
\text { strain guages }\end{array}$ \\
\hline $\begin{array}{l}\text { Morita (1994) } \\
\text { Rectangle specimens } \\
\text { Square } \mathrm{c} / \mathrm{s}=12 * \varphi \\
\text { Length }=60 * \varphi \\
\text { Strain gauge only on rebar. } \\
\text { Spacing }=5 * \varphi\end{array}$ & $\begin{array}{l}\text { Concrete strain is } \\
\text { neglected when calculating } \\
\text { the slip, assuming the } \\
\text { domination contributor to } \\
\text { the slip is the internal } \\
\text { cracks. }\end{array}$ & $\begin{array}{l}\text { Bond-slin model } \\
\text { identified by } \\
\text { (Muguruma, } \\
\text { Morita, and } \\
\text { Yoshida, 1967) } \\
\frac{\mathrm{d}^{2} \mathrm{ys}(\mathrm{x})}{\mathrm{d} x^{2}} \\
4(1+\mathrm{np})\end{array}$ & $\begin{array}{l}\text { Slip is identified } \\
\text { from the steel } \\
\text { strain, neglecting } \\
\text { concrete strain. } \\
\text { Slip of the } \\
\text { element ' } a+1 \text { ', } \\
\mathrm{S}(\mathrm{a}+1)(\mathrm{x})=\varepsilon_{\mathrm{s}, \mathrm{a}} \cdot \mathrm{dx}\end{array}$ \\
\hline $\begin{array}{l}\text { Beconcini et al. (2008) } \\
\text { or free at https//Www.sc } \\
\text { Cylindrical specimen dia.= } \\
132 \mathrm{~mm} . \\
\text { Length }=1000 \mathrm{~mm} . \\
\text { Bar dia. }=16 \mathrm{~mm} \\
\text { Strain gauge only on rebar. } \\
\text { Spacing }=25 \mathrm{~mm}\end{array}$ & 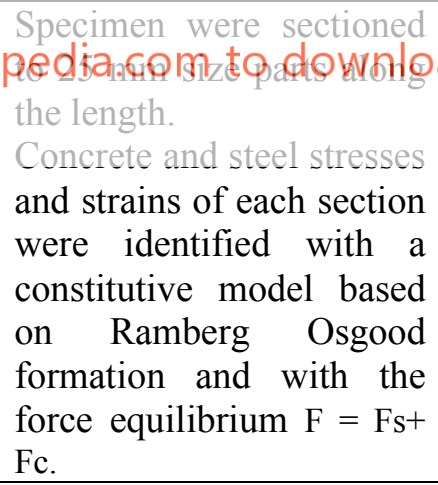 & 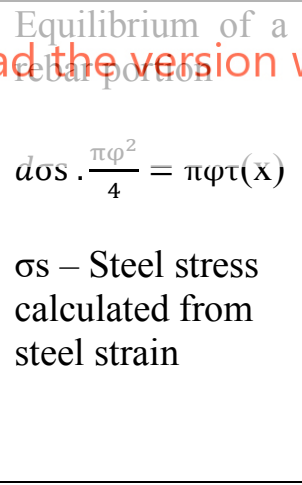 & $\begin{array}{l}\text { From the } \\
\text { vitderiutitlaes mat } \\
\qquad \frac{d s}{d x}=\varepsilon s-\varepsilon c\end{array}$ \\
\hline
\end{tabular}

When considering the bond-slip behavior of the specimens subjected to axial tension, it can be concluded that the 'bond-slip' theory can cause a negligible influence on crack spacing. Therefore the involvement of $\varnothing / \rho_{\mathrm{p}, \text { ef }}$ parameter on crack spacing behavior have to be reconsidered. Further This description ends with agreeing the conclusion of Beeby (2004), that the $\varnothing / \rho_{\mathrm{p}, \mathrm{ef}}$ parameters has a negligible effect, while concrete cover thickness has a significant effect on crack spacing and therefore to the crack width.

\section{Summary and Conclusions}

Concrete cover thickness and $\emptyset / \rho_{\mathrm{p}, \text { ef }}$ parameter have identified as governing parameters of crack spacing models in Eurocode 2 and Model code 2010. From the recent experimental results, it 
could be identified that the concrete cover thickness has a significant effect on crack spacing. However, the $\emptyset / \rho_{\mathrm{p} \text {,ef }}$ parameter, which present in the crack spacing model due to the 'bond-slip theory' has an negligible influence to the crack spacing. A possible reason for that can be the effect of different rib indexes of different bar sizes, which is not taken into account in the abovementioned crack spacing models. Experimental results showed similar crack spacing values using low number of large bar diameters and high number of small bar diameters. Therefore, the bond per unit surface area have to be higher in large diameter bars than small diameter bars. A literature survey is carried out to identify the aforementioned effect and it is found that, the bond per unit surface area is getting lower with the increase of bar diameter. Moreover, it is vital to investigate the applicability of Rilem-type pull-out test results to study the bond behavior in a RC tie. The main contradiction is the, obtained slip value in axial tension is significantly smaller than Rilem-type pull-out tests. Further, there is an argument that the internal cracks contribute to the slip. However, the results of Yannopoulos (1989) have proved that the internal cracks do not have a significant contribution to the slip. Further, Beeby (2004) have experimentally proved that there is no slip occurred at the reinforcement-concrete interface of an RC tie in pure tension. Moreover, as mentioned in the available studies on bond-slip behavior subjected to axial tension, have not measured the concrete strain separately, to measure the slip value. Therefore, it can be concluded that the mentioned crack spacing models have overestimated the effect of bond-slip behavior.

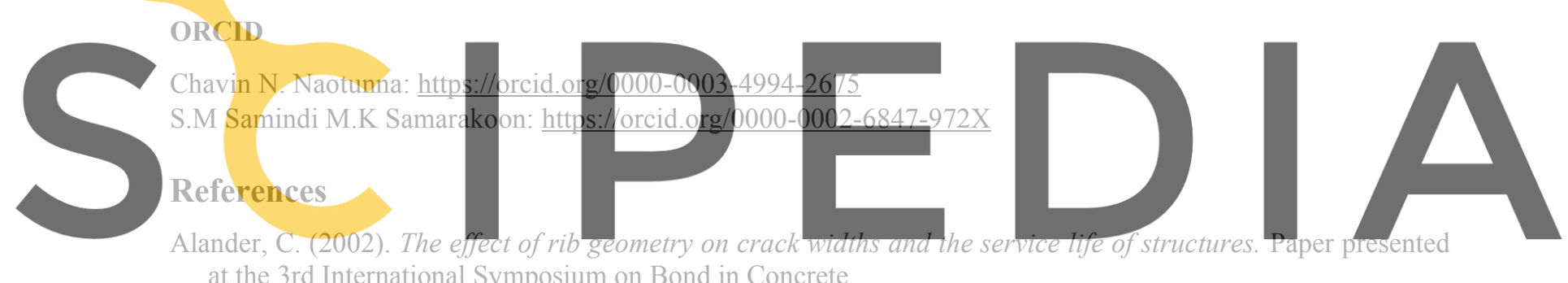

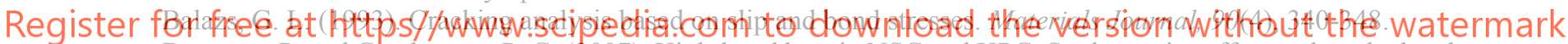

Bamonte, P. and Gambarova, P. G. (2007). High-bond bars in NSC and HPC: Study on size effect and on the local bond stress-slip law. Journal of Structural Engineering, 133(2), 225-234.

Bažant, Z. P., Li, Z. and Thoma, M. (1995). Identification of stress-slip law for bar or fiber pullout by size effect tests. Journal of engineering mechanics, 121(5), 620-625.

Beconcini, M. L., Croce, P. and Formichi, P. (2008). Influence of bond-slip on the behaviour of reinforced concrete beam to column joints. Paper presented at the Proceedings of International fib Symposium "Taylor Made Concrete Structures: New Solutions for our Society.

Beeby, A. W. (2004). The influence of the parameter $\phi / \rho$ eff on crack widths. Structural Concrete, 5(2), 71-83.

Beeby, A.W.,C. Å., J. Cairns, R. Eligehausen, U. Mayer, S. Lettow, Daniele Ferretti, I. Iori, Pietro G. Gambarova, Patrick Bamonte, Ezio Giuriani, Giovanni A. Plizzari, Stavroula Pantazopoulou and Souzana Tastani. (2005). Discussion : The influence of the parameter $\varphi /$ peff on crack widths. Structural Concrete, 6(4):155-165. doi:10.1680/stco.2005.6.4.155

Borosnyói, A. and Snóbli, I. (2010). Crack width variation within the concrete cover of reinforced concrete members. Épitõanyag, 62(3), 70-74.

Broms, B. B. (1965). Crack width and crack spacing in reinforced concrete members. Paper presented at the ACI Journal Proceedings.

CEN. (2004). EN: EN 1992-1-1, Eurocode 2: Design of concrete structures - Part 1-1: General rules and rules for buildings In. Brussels: European Committee for Standardization.

Ciampi, V., Eligehausen, R., Bertero, V. V. and Popov, E. P. (1981). Analytical model for deformed bar bond under generalized excitations.

Ciampi, V., Eligehausen, R., Bertero, V. V. and Popov, E. P. (1982). Analytical model for concrete anchorages of reinforcing bars under generalized excitations: College of Engineering, University of California Berkeley, CA, USA.

Debernardi, P. G., Guiglia, M. and Taliano, M. (2013). Effect of secondary cracks for cracking analysis of reinforced concrete tie. ACI Materials Journal, 110(2), 207. 
Debernardi, P. G. and Taliano, M. (2016). An improvement to Eurocode 2 and fib Model Code 2010 methods for calculating crack width in RC structures. Structural Concrete, 17(3), 365-376.

Doerr, K. (1978). Bond behavior of ribbed reinforcement under transversal pressure. Paper presented at the Nonlinear behavior of reinforced concrete structures; contributions to IASS symposium.

Farra, B. and Jaccoud, J.-P. (1994). Influence du béton et de l'armature sur la fissuration des structures en béton: rapport des essais de tirants sous déformation imposée de courte durée. Retrieved from

fib. (2013). fib Model Code for concrete structures 2010. In Structural Concrete. Berlin: Ernst and Sohn.

Goto, Y. (1971). Cracks formed in concrete around deformed tension bars. Paper presented at the Journal Proceedings.

Haqqi, S. (1983). Serviceability of reinforced concrete subjected to tension. Polytechnic of Central London,

Husain, S. I. and Ferguson, P. M. (1968). Flexural crack width at the bars in reinforced concrete beams.

Mazzarolo, E., Scotta, R., Berto, L. and Saetta, A. (2012). Long anchorage bond-slip formulation for modeling of rc elements and joints. Engineering Structures, 34, 330-341.

Metelli, G. and Plizzari, G. A. (2014). Influence of the relative rib area on bond behaviour. Magazine of Concrete Research, 66(6), 277-294.

Morita, S. (1994). Experimental study on size effect in concrete structures. Size effect in concrete structures, $27-$ 46.

Muguruma, H., Morita, S. and Yoshida, H. (1967). Fundamental study on bond between steel and concrete. Transaction of Architectural Institute of Japan, 131, 1-6.

Noghabai, K. (1995). Splitting of concrete in the anchoring zone of deformed bars: a fracture mechanics approach to bond. Luleå tekniska universitet,

Pérez Caldentey, A., Corres Peiretti, H., Peset Iribarren, J. and Giraldo Soto, A. (2013). Cracking of RC members revisited: influence of cover, $\phi / \rho s$, ef and stirrup spacing-an experimental and theoretical study. Structural Concrete, 14(1), 69-78.

RILEM, T. (1994). RC 6 Bond test for reinforcement steel. 2. Pull-out test, 1983. RILEM recommendations for the testing and use of constructions materials, 218-220.

Rimkus, A. and Gribniak, V. (2017). Experimental inv reinforced with multip

Saliger, R. (1936). High Congress of IABSE. Berii

Shima, H., Chou, L.-L. and O of the Faculty of Engineer

Tammo, K. and Thelanderts Concrete, 10(1), 27-34

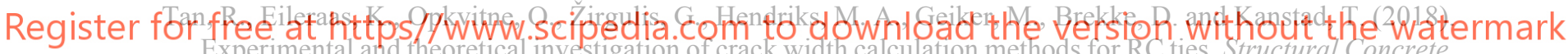
$19(5), 1436-1447$

Tan, R., Max, A. N., Hendriks, Mette, G. and Terje, K. (2019). Analytical calculation model for predicting the cracking behavior of reinforced concrete ties. Structural Engineering.

Yannopoulos, P. (1989). Variation of concrete crack widths through the concrete cover to reinforcement. Magazine of Concrete Research, 41(147), 63-68. 